\title{
Nuclear Pore Complex Protein Nup107
}

National Cancer Institute

\section{Source}

National Cancer Institute. Nuclear Pore Complex Protein Nup107. NCI Thesaurus. Code C101489.

Nuclear pore complex protein Nup107 (925 aa, 106 kDa) is encoded by the human NUP107 gene. This protein is involved in nuclear pore assembly. 